\title{
First record of the tribe Naupactini (Coleoptera: Curculionidae) in Rovno amber
}

\author{
Andris Bukejs ${ }^{1}$ and Andrei A. Legalov ${ }^{2,3}$ \\ ${ }^{1}$ Institute of Life Sciences and Technologies, Daugavpils University, Vienības 13, Daugavpils, 5401, Latvia \\ ${ }^{2}$ Institute of Systematics and Ecology of Animals, Siberian Branch, Russian Academy of Sciences, Frunze Street, 11, \\ Novosibirsk 630091, Russia \\ ${ }^{3}$ Tomsk State University, Lenina Prospekt 36, Tomsk 634050, Russia
}

Correspondence: Andrei A. Legalov (fossilweevils@gmail.com)

Received: 4 March 2019 - Accepted: 22 March 2019 - Published: 18 April 2019

\begin{abstract}
A new weevil, Arostropsis perkovskyi Bukejs and Legalov, sp. nov. (urn:lsid:zoobank.org:act:408ECE71B191-4381-AA39-C27A3A1DA082; Coleoptera: Curculionidae: Entiminae), is described from Late Eocene Rovno amber. The new species differs from Arostropsis groehni Yunakov et Kirejtshuk, 2011 from Baltic amber in the pronotum lacking a distinct lateral ridge, it has a shorter rostrum, antennomere 2 is subequal to antennomere 3 , it has wider elytra with weaker convex humeral calli and the pronotum is wider than it is long. It is the first record of the tribe Naupactini in Rovno amber and the second finding of Arostropsis in Eocene ambers.
\end{abstract}

\section{Introduction}

The subfamily Entiminae is the richest in species among the Curculionidae. The oldest representative of the subfamily is known from the Paleocene of Menat (Legalov et al., 2017). Many species are known or are recorded from Eocene ambers and impressions (Legalov, 2015). Members of different tribes were described from the earliest Eocene Oise (Legalov et al., 2019a) and Late Eocene Baltic ambers (Voss, 1953, 1972; Zherikhin, 1971; Wanat and Boroviec, 1986; Yunakov and Kirejtshuk, 2011; Legalov, 2012, 2013, 2016; Legalov and Bukejs, 2015). Unique fauna was found in Miocene Dominican amber (Poinar Jr. et al., 2013; Franz and Zhang, 2017; Poinar Jr. and Legalov, 2017). However, not enough data are available to study the phylogeny of this subfamily. Each new find contributes to the knowledge of the evolution of this group. In this paper we describe a second species of the extinct amber genus Arostropsis Yunakov et Kirejtshuk, 2011 belonging to the tribe Naupactini.

\section{Material and methods}

The material examined comes from the collection of Carsten Gröhn (Glinde, Germany) and is deposited in the Center of Natural History (CeNak) (formerly GeologicalPaleontological Institute and Museum, GPIH) of the University of Hamburg, Germany. The amber piece was polished by hand, allowing improved views of the included specimen, and was not subjected to any supplemental fixation.

Observations of this specimen were made using a Nikon $\mathrm{SMZ}^{\circledR}$ 745T stereomicroscope. The photographs were taken using a Canon $70 D^{\circledR}$ camera with a macro lens (Canon MPE$65 \mathrm{~mm}$ ). Extended depth of field at high magnifications was achieved by combining multiple images from a range of focal planes using Helicon Focus ${ }^{\circledR}$ v. 6.0.18 software. Measurements were taken using an ocular micrometer (expressed in millimeters).

The morphological terminology used in this paper follows Lawrence et al. (2010).

\section{Systematic paleontology}

Family Curculionidae Latreille, 1802

Subfamily Entiminae Schoenherr, 182

Tribe Naupactini Gistel, 1848

Genus Arostropsis Yunakov et Kirejtshuk, 2011 
Arostropsis perkovskyi sp. nov.

Figs. 1-2

\section{Etymology}

The species is named after Evgeny E. Perkovsky (Kiev), a researcher of extinct insect fauna preserved in fossil resins.

\section{Holotype}

Holotype: "GPIH 4981, coll. Gröhn 8591", deposited in the Center of Natural History (CeNak) (formerly GeologicalPaleontological Institute and Museum, GPIH) of the University of Hamburg, Germany; Rovno amber; adult, female. Complete beetle with partially exposed metathoracic wings is included in elongate, transparent amber piece, with dimensions of $50 \times 22 \times 12 \mathrm{~mm}$.

Syninclusions: three small specimens of Araneae, one specimen of an aphid (Hemiptera, Sternorrhyncha, Aphidoidea), a leg of Opiliones (Arachnida), antennae of an unknown insect, many stellate Fagaceae trichomes, unclear and stellate trichomes, and a few pieces of organic material.

\section{Description}

Size: Body length $6.8 \mathrm{~mm}$, maximum width $2.1 \mathrm{~mm}$; elongate, slightly convex dorsally; integument unicolorous, brown, densely covered with small elongated oval to widely oval, pale brown (dorsally) and yellowish-white (ventrally and on legs) scales.

Head: prognathous, without constriction beyond eyes, maximum width at posterior part of eye; densely covered with minute punctation, distance between punctures lesser than diameter of one puncture. Rostrum short, about 1.2 times as long as it is wide, distinctly narrower than head capsule; antennal scrobes lateral; pterygia weakly extending beyond lateral contour of rostrum; epifrons almost flat, without transverse impression or sulcus; median sulcus distinct, not continuing towards vertex. Forehead slightly convex, about 2 times as wide as the width of epifrons at the level of antennal insertions. Vertex apparently without distinct fossa. Compound eyes large, subspherical, strongly convex, lateral, with distinct facets. Mandibles massive, with scar of deciduous process, without scales; deciduous process apparently without inner basal tooth. Antennae geniculate, with 11 antennomeres, clavate, with distinct three-segmented club; moderately long, reaching base of elytra, apparently sparsely covered with fine, short setae; scape comparatively short, not extending beyond anterior one-fifth of eyes, slightly dilated apically, about 0.3 times as long as antennomeres 2-8 (funicle) combined, 2 times as long as antennomere 2, antennomeres 2-8 elongate, subcylindrical, antennomere 2 about 2.1 times as long as it is wide, antennomere 3 subequal to antennomere 2; antennomere 7 about 2 times as long as wide, antennal club spindle shaped, comparatively short and thin, about as long as antennomeres $2-3$ combined, antennomere 10 about 1.7 times as wide as antennomere 7 , antennomere 11 oval with tapered apex; relative length ratios of antennomeres 111 equal to $10: 5: 5: 4: 4: 4: 4: 4: 3: 2: 5$.

Pronotum: slightly transverse, 1.3 times as wide as it is long, almost parallel sided, without distinct lateral ridge, with anterior constriction, widest medially, slightly narrowed posteriad and anteriad, disc slightly convex; densely covered with small punctation, distance between punctures lesser than diameter of one puncture; lateral margins evenly slightly convex, anterior margin almost straight, posterior margin slightly convex. Scutellum small, subtriangular with rounded apex, with fine punctures.

Elytra: elongate, about 2.1 times as long as it is wide, parallel sided, declivity gently sloping, humeral calli distinct, weakly convex, basal margin slightly concave. Elytral punctures distinctly larger in basal portion than in apical, dense, arranged in regular rows, distance between rows about 2-5 times the diameter of puncture, rows less distinct at apices, distance between punctures in rows equal to 1-2 times the diameter of puncture, intervals weakly and indistinctly convex; sutural stria lacking. Macropterous.

Metaventrite: slightly convex, with small, round, glabrous fossa posteromedially, and with transverse sulcus posterolaterally; metepisternum narrow, widest at anterior margin, about 4.1 times as long as it is wide. Abdomen with five visible ventrites, abdominal sutures distinct throughout length, intercoxal process of ventrite 1 widely rounded; ventrites $1-5$ oriented in one plane; ventrite 1 with shallow, oval impression medially; ventrites 1 and 2 elongate and fused; ventrite 5 with rounded apex; relative length ratios of abdominal ventrites $1-5$ equal to $10: 5$ (medially).

Legs: moderately long, slender. Procoxae hemispherical, contiguous, located in middle of prothorax; mesocoxae hemispherical, narrowly separated by 0.2 times the diameter of mesocoxa; metacoxae transverse, about 3.2 times as wide as it is long, narrowly oval, separated by 0.5 times the transverse diameter of metacoxa. Femora elongate, clavate, slightly swollen in apical half; metafemora slightly curved, their interior side with ovale glabrous (without scales and punctures) area. Tibiae slender, elongate, nearly as long as femora, almost straight (pro- and mesotibiae slightly curved inwards in apical one-fourth), with small short spine and fringe of spinula apically; corbels open, without additional row of spines, without uncus and bunches of setae. Tarsi slender, long, setaceous, pelma well-developed; tarsomere 1 dilated apically, about as long as tarsomeres 2 and 3 combined, tarsomere 2 about 0.7 times as long as tarsomere 1, tarsomere 3 deeply bilobed, transverse, ultimate tarsomere elongate, projecting from tarsomere 3 to about half of its length. Tarsal claws free, simple. 


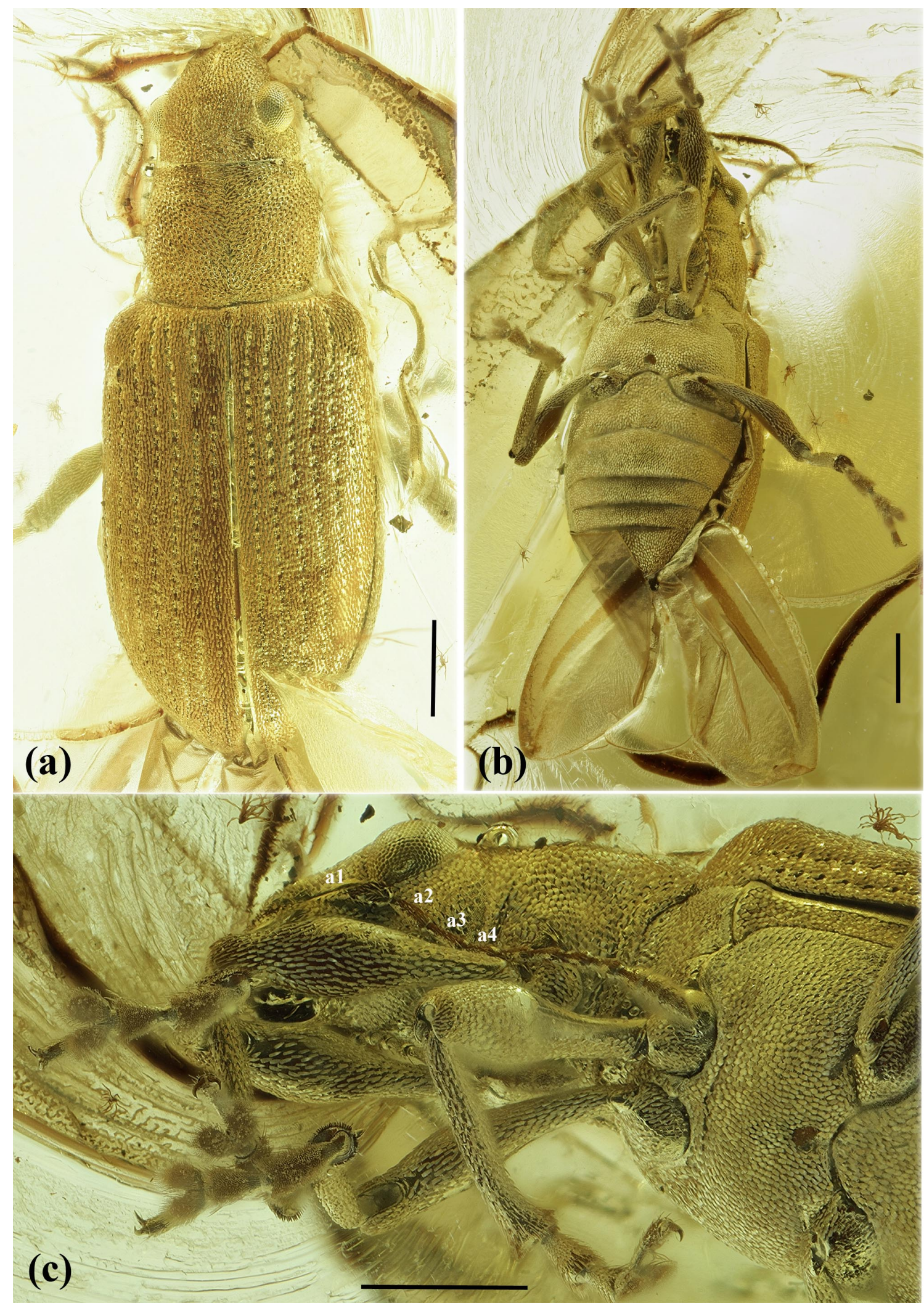

Figure 1. Arostropsis perkovskyi sp. nov., holotype: (a) habitus, dorsal view; (b) habitus, ventral view; (c) forebody, ventrolateral view. Scale bars $=1 \mathrm{~mm}$. Abbreviations: a1-a4 denote antennomeres $1-4$, respectively. 

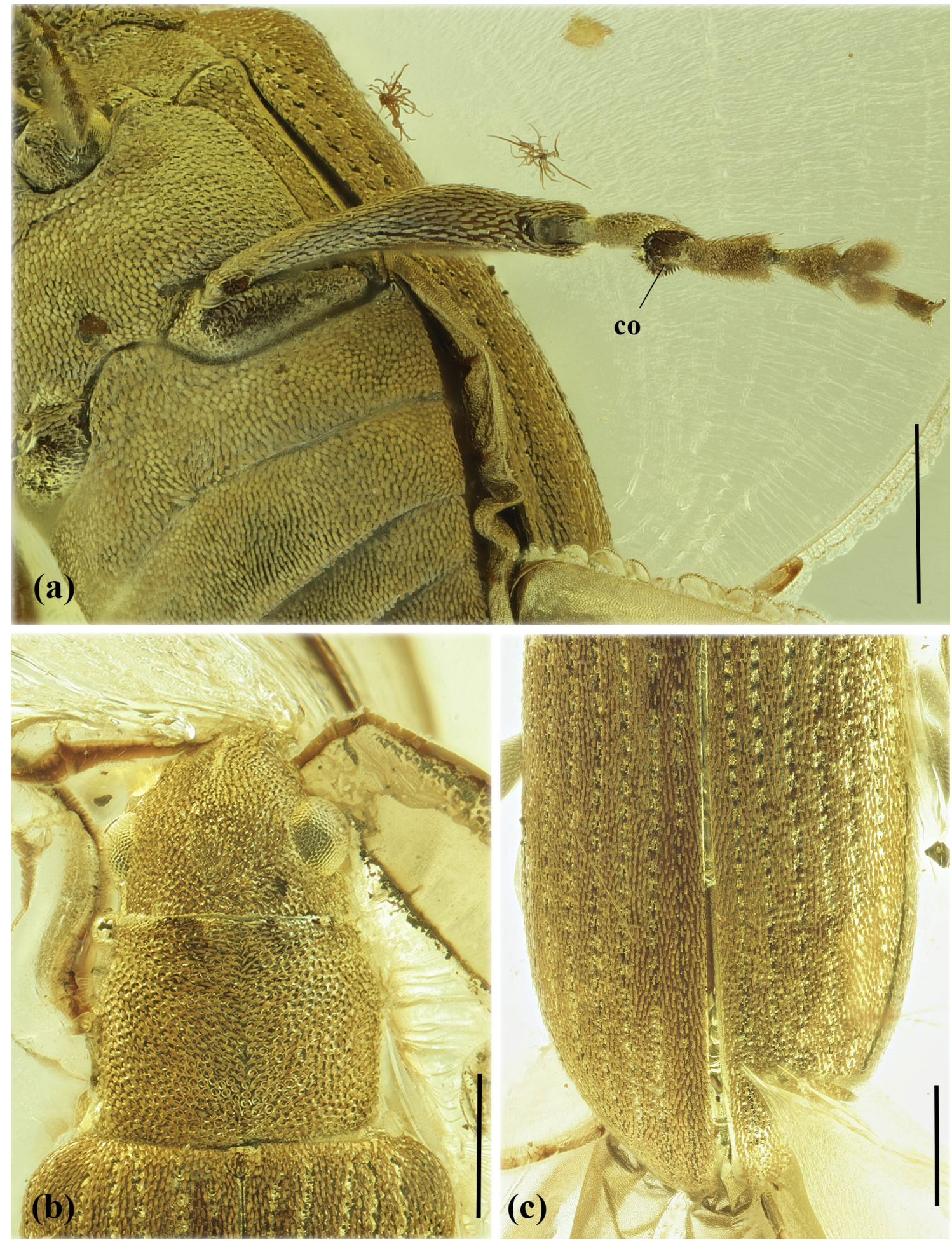

Figure 2. Arostropsis perkovskyi sp. nov., holotype: (a) details of metathorax and abdomen, ventral view; (b) forebody, dorsal view; (c) details of elytra, dorsal view. Scale bars $=1 \mathrm{~mm}$. Abbreviations: co - corbel. 


\section{Comparison}

The new species differs from Arostropsis groehni Yunakov et Kirejtshuk, 2011 from Baltic amber in the pronotum lacking a distinct lateral ridge, shorter rostrum, antennomere 2 subequal to antennomere 3 , wider elytra with weaker convex humeral calli and a pronotum wider than it is long.

\section{Remarks}

The geniculate antennae, elongate and fused ventrites 1 and 2 , and ventrites $1-5$ oriented in one plane, suggest placement of new species in the family Curculionidae. The massive mandibles, with a scar of the deciduous process, tibiae without an uncus and bunches of setae, suggest placement in the subfamily Entiminae. Placement of this species in the tribe Naupactini is based on the almost flat epifrons, without a transverse impression or sulcus, free tarsal claws, lateral antennal scrobes and eyes. The new species belongs to the genus Arostropsis based on open corbels and a scape comparatively short, not extending beyond the anterior one-fifth of eyes.

\section{Discussion}

The tribe Naupactini is rich in species and distributed mainly in the New World (Alonso-Zarazaga and Lyal, 1999). Only five fossil species are known in this tribe (Legalov, 2015). The oldest representative of Entiminae from the Paleocene of France probably belongs to the Naupactini (Legalov et al., 2017). The first member of the genus Arostropsis is known from Baltic amber (Yunakov and Kirejtshuk, 2011). Two species were found from the terminal Eocene of Florissant (Wickham, 1911, 1914). The extinct subtribe Brachycamacina was described from Dominican amber (Poinar Jr. et al., 2013).

Seven weevil species from the subfamilies Dryophthorinae, Cossoninae, Curculioninae and Entiminae are known from Rovno amber so far (Nazarenko and Perkovsky, 2009, 2016; Nazarenko et al., 2011; Legalov et al., 2019b). Two species of the entimine weevils in the genus Paonaupactus Voss, 1953 of the tribe Anypotactini will be described soon (Legalov et al., 2019b). No members of other tribes have been so far recorded from this fossil resin.

Data availability. All material included in the paper is accessible in the collection of Carsten Gröhn (Glinde, Germany) and is deposited in the Center of Natural History (CeNak) (formerly GeologicalPaleontological Institute and Museum, GPIH) of the University of Hamburg, Germany, and all data are included in the description.

Author contributions. AB and AAL prepared the paper and contributed to the editing.
Competing interests. The authors declare that they have no conflict of interest.

Acknowledgements. The authors are sincerely grateful to Carsten Gröhn (Glinde, Germany) for the loan of interesting fossil material, to Jonas Damzen (Vilnius, Lithuania) for permission to use his photographs and to George O. Poinar Jr. (Corvallis, USA) for improving the paper. The study was partially supported by the Russian Foundation for Basic Research, project nos. 18-04-00243-a and 19-04-00465-a and the Federal Fundamental Scientific Research Program for 2013-2020, project no. AAAA-A16-116121410121-7.

Review statement. This paper was edited by Florian Witzmann and reviewed by Leonid Friedman and one anonymous referee.

\section{References}

Alonso-Zarazaga, M. A. and Lyal, C. H. C.: A world catalogue of families and genera of Curculionoidea (Insecta: Coleoptera), Entomopraxis, Barcelona, Spain, 1999.

Franz, N. and Zhang, G.: Three new species of entimine weevils in Early Miocene amber from the Dominican Republic (Coleoptera: Curculionidae), Biodiversity Data J., 5, 1-23, https://doi.org/10.3897/BDJ.5.e10469, 2017.

Lawrence, J. F., Beutel, R. G., Leschen, R. A. B., and Slipinski, S. A.: Chapter 2. Glossary of Morphological Terms, in: Handbook of Zoology. Arthropoda: Insecta. Tb. 40: Coleoptera (Beetles), Vol. 2: Morphology and Systematics (Elateroidea, Bostrichformia, Cucujiformia partim), Berlin, New York: Walter de Gruyter, 9-20, 2010.

Legalov, A. A.: New Curculionoid beetles (Coleoptera: Curculionoidea) from the Baltic amber, Paleontol. J., 46, 262-272, https://doi.org/10.1134/S0031030112030094, 2012.

Legalov, A. A.: New and little known weevils (Coleoptera: Curculionoidea) from the Paleogene and Neogene, Hist. Biol., 25, 59-80, https://doi.org/10.1080/08912963.2012.692681, 2013.

Legalov, A. A.: Fossil weevils (Coleoptera, Obrienioidea, Curculionoidea) from Mesozoic and Cainozoic, Paleontol. J., 49, 1442-1513, https://doi.org/10.1134/S0031030115130067, 2015.

Legalov, A. A.: Two new genera and four new species of fossil weevils (Coleoptera: Curculionoidea) in Baltic amber, Entomol. Fennica, 27, 57-69, 2016.

Legalov, A. A. and Bukejs, A.: A new species of the genus Archaeocallirhopalus (Coleoptera: Curculionidae) in Baltic amber, Entomol. Fennica, 26, 25-29, 2015.

Legalov, A. A., Nel, A., and Kirejtshuk, A. G.: New and little known weevils (Coleoptera: Curculionoidea) from the Paleocene of Menat (France), C. R. Palevol., 16, 248-256, https://doi.org/10.1016/j.crpv.2016.10.007, 2017.

Legalov, A. A., Kirejtshuk, A. G., and Nel, A.: New weevils (Coleoptera, Curculionoidea) from the earlymost Eocene Oise amber, Paleontol. J., 53, in press, 2019a.

Legalov, A. A., Nazarenko, V. Y., and Perkovsky, E. E.: New weevils (Coleoptera: Curculionidae) from the Rovno amber, Paleontol. J., 53, in press, 2019 b. 
Nazarenko, V. Y. and Perkovsky, E. E.: A new genus and species of Dryophthorid weevils (Coleoptera, Dryophthoridae: Stromboscerinae) from the Rovno amber, Paleontol. J., 43, 1097-1100, https://doi.org/10.1134/S003103010909010X, 2009.

Nazarenko, V. Y. and Perkovsky, E. E.: A new species of Derelomine weevils (Coleoptera, Curculionidae, Curculioninae: Acalyptini) from the Rovno amber, Paleontol. J., 50, 991-996, https://doi.org/10.1134/S0031030116090094, 2016.

Nazarenko, V. Y., Legalov, A. A., and Perkovsky, E. E.: A new species of the genus Caulophilus Woll. (Coleoptera: Curculionidae: Cossoninae) from the Rovno amber, Paleontol. J., 45, 287290, https://doi.org/10.1134/S0031030111030105, 2011.

Poinar Jr., G. and Legalov, A. A.: Five new species from the subfamily Entiminae (Coleoptera: Curculionidae) in Dominican amber, Palaeontol. Electron., 20, 1-13, https://doi.org/10.26879/698, 2017.

Poinar Jr., G., Legalov, A. A., and Brown, A. E.: Brachycamacina, a new subtribe of the tribe Naupactini (Coleoptera: Curculionidae: Entiminae) in Dominican amber, Palaeontol. Electron., 16, 1-9, https://doi.org/10.26879/698, 2013.

Voss, E.: Einige Rhynchophoren der Bernsteinfauna (Coleoptera), Mitt. Geol. Staat. Hamburg, 22, 119-140, 1953.
Voss, E.: Einige Rüsselkäfer der Tertiärzeit aus Baltischen Bernstein (Coleoptera, Curculionidea), Steenstupia, 2, 167-181, 1972.

Wickham, H. F.: Fossil Coleoptera from Florissant, with descriptions of several new species, B. Am. Mus. Nat. Hist., 30, 53-69, 1911.

Wickham, H. F.: New Miocene Coleoptera from Florissant, Bulletin of the Museum of Comparative Zoology, 58, 423-494, 1914.

Wanat, M. and Boroviec, L.: New genus of weevil (Coleoptera, Curculionidae) from Baltic amber, Polskie Pismo Entomologiczne, 56, 243-247, 1986.

Yunakov, N. N. and Kirejtshuk, A. G.: New genus and species of broad-nosed weevils from Baltic amber and notes on fossils of the subfamily Entiminae (Coleoptera, Curculionidae), ZooKeys, 160, 73-96, https://doi.org/10.3897/zookeys.160.2108, 2011.

Zherikhin, V. V.: O dolgonosikach (Insecta, Coleoptera) Baltiyskogo Jantarja [On the weevils (Insecta, Coleoptera) from the Baltic Amber], Trudy Palaeontologicheskogo Instituta, Moscow, 130, 197-209, 1971. 